\title{
Pengaruh Pesan Persuasif Beauty Vlogger terhadap Keputusan Pembelian
}

\author{
Cindy Claudia Christine, Roswita Oktavianti \\ cindyclaudia.christine@yahoo.co.id,roswitao@fikom.untar.ac.id
}

Fakultas Ilmu Komunikasi Universitas Tarumanagara

\begin{abstract}
Persuasive communication is one of the studies of communication that is often used as a method of influencing others in various ways, including in the field of sales. Persuasive messages are seen as a conscious effort to change thoughts and actions by manipulating motives in the direction of a predetermined goal. Decision making is an integration process that combines knowledge to evaluate two or more alternative behaviors and choose one of them. The independent variable in this study is persuasive messages and the dependent variable is the purchasing decision. This type of research is quantitative descriptive. The research data collected uses non probability sampling and purposive sampling techniques. This study uses SPSS for Windows 15 test for Validity, Reliability, Simple Linear Analysis Hypothesis, Correlation Coefficient, Determination Coefficient, Regression Analysis, and TTest. and represent the population. The results of research conducted by researchers that persuasive messages influence as much as $39.4 \%$ in purchasing decisions, while the remaining $60.6 \%$ is influenced by other factors. Research also shows that if persuasive messages are improved, purchasing decisions will also increase.
\end{abstract}

Keywords: Beauty Vlogger, Persuasive Message, Purchasing Decision.

\begin{abstract}
Abstrak
Komunikasi persuasif merupakan salah satu kajian komunikasi yang kerap digunakan sebagai metode mempengaruhi orang lain dalam berbagai hal, termasuk diantaranya dalam bidang penjualan. Pesan persuasif dipandang sebagai usaha sadar untuk mengubah pikiran dan tindakan dengan memanipulasi motif-motif ke arah tujuan yang telah ditetapkan. Pengambilan keputusan merupakan sebuah proses pengintegrasian yang mengkombinasikan pengetahuan untuk mengevaluasi dua atau lebih perilaku alternatif dan memilih salah satu diantaranya. Variabel independen dalam penelitian ini adalah pesan persuasif dan variabel dependen adalah keputusan pembelian. Jenis penelitian ini adalah deskriptif kuantitatif. Data penelitian yang dikumpulkan ini menggunakan non probability sampling dan teknik purposive sampling. Penelitian ini menggunakan alat uji SPSS for windows 15 untuk Uji Validitas, Reliabiltas, Hipotesis analisis linier sederhana, Koefisien Korelasi, Koefisien Determinasi, Analisis Regresi, dan Uji T. Peneliti memperoleh data dengan menyebarkan kuesioner kepada 100 responden yang sudah ditentukan dan sesuai dengan syarat penelitian dan mewakili populasi. Hasil penelitian yang dilakukan oleh peneliti bahwa pesan persuasif berpengaruh sebanyak $39,4 \%$ pada keputusan pembelian, sementara sisanya $60,6 \%$ dipengaruhi oleh faktor lain. Penelitian juga menunjukan bahwa apabila pesan persuasif ditingkatkan maka keputusan pembelian juga akan meningkat.
\end{abstract}

Kata kunci: Beauty Vlogger, Keputusan Pembelian, Pesan Persuasif. 
Cindy Claudia Christine, Roswita Oktavianti: Pengaruh Pesan Persuasif Beauty Vlogger terhadap Keputusan Pembelian

\section{Pendahuluan}

Komunikasi merupakan suatu hal yang tidak bisa lepas dari kehidupan manusia. Mulai dari interaksi dalam kegiatan sehari-hari, hingga pengembangan ilmu di berbagai bidang, membutuhkan aktivitas komunikasi. Dalam proses komunikasi terjadi transmisi pesan oleh komunikator dan interpretasi oleh komunikan. Steward dan Sylvia (dalam Syamsurizal 2016) mengemukakan bahwa suatu komunikasi dikatakan efektif apabila menimbulkan pengaruh pada sikap seseorang. Artinya, komunikasi yang efektif berarti mampu mempengaruhi sikap seseorang. Upaya komunikasi untuk mempengaruhi sikap seseorang ini kemudian disebut sebagai komunikasi persuasif.

Menurut DeVito (2011:499), usaha melakukan persuasi ini memusatkan perhatian pada upaya mengubah atau memperkuat sikap atau kepercayaan khalayak atau pada upaya mengajak mereka bertindak dengan cara tertentu. Sementara menurut Littlejohn, pesan persuasif dipandang sebagai usaha sadar untuk mengubah pikiran dan tindakan dengan memanipulasi motif-motif ke arah tujuan yang telah ditetapkan (dalam Ritonga, 2005:5). Pesan persuasif memiliki peranan yang penting dalam membantu strategi periklanan seiring dengan berjalannya waktu. Dengan memakai internet akan membantu dalam menyebarkan informasi sehingga calon pembeli dapat lebih mudah untuk meyakinkan untuk membeli produk tersebut.

Menurut Amirullah, keputusan pembelian dapat didefinisikan sebagai suatu proses di mana konsumen melakukan penilaian terhadap berbagai alternatif pilihan dan memilih salah satu atau lebih alternatif yang diperlukan berdasarkan pertimbangan tertentu. Keputusan pembelian yang dilakukan oleh konsumen menggambarkan seberapa jauh tingkat pengaruh usaha pemasaran yang dilakukan terhadap suatu produk sehingga pemasar harus mengetahui perilaku konsumen dalam hal menentukan keputusan pembeliannya (dalam Hidayati, Suharyono dan Fanani, 2013). Terlihat bahwa keputusan pembelian merupakan kegiatan individu yang secara langsung terlibat dalam pengambilan keputusan untuk melakukan pembelian terhadap produk yang ditawarkan oleh penjual.

Fenomena media sosial yang sangat digandrungi saat ini adalah Youtube. Youtube sebagai salah satu platform audio visual sudah sejak lama mendapat perhatian tersendiri dari masyarakat Salah satu konten yang akhir-akhir ini sedang digemari oleh penonton Youtube adalah konten video blog atau yang biasa disebut dengan Vlog. Fenomena ini ikut memunculkan pula hadirnya Beauty Vlogger yaitu para pembuat konten yang mengkhususkan dirinya untuk berbagi informasi terkait dunia kecantikan. Kemunculan beauty vlogger saat ini dirasa memudahkan pengguna dalam hal ini sebagai calon konsumen untuk mengenal brand maupun produk yang ingin mereka gunakan.

Salah satu Beauty Vlogger Indonesia, Tasya Farasya menjadi semakin terkenal karena unggahan video Youtubenya yang menarik dan inspiratif. Hingga saat ini seluruh video Tasya yang ada di YouTube sudah ditonton lebih dari 233 juta kali. Berkat ide-ide kreatifnya tersebut, wanita yang memiliki nama asli Lulu Farassiya itu kini menjadi terkenal dan memiliki jutaan pengikut di media sosialnya. Di akun Youtubenya, Tasya telah memiliki 3 juta lebih pengikut dan akun Instagram pribadinya diikuti lebih dari 2,8 juta pengguna (wolipopdetik, 2020). Berdasarkan latar belakang tersebut, maka rumusan masalah dalam penelitian ini adalah, apakah pesan persuasif beauty vlogger berpengaruh terhadap keputusan pembelian, dan Seberapa besar pengaruh pesan persuasif beauty vlogger terhadap keputusan pembelian. Tujuan 
penelitian ini adalah, untuk mengetahui adakah pengaruh pesan persuasif beauty vlogger terhadap keputusan pembelian, dan untuk mengetahui seberapa besar pengaruh pesan persuasif beauty vlogger terhadap keputusan pembelian.

\section{Metode Penelitian}

Gambar 1. Variabel X dan Variabel Y

\begin{tabular}{|c|c|}
\hline Pesan persuasif: & Keputusan pembelian: \\
(X) & $(Y)$ \\
Perhatian & Pengenalan masalah \\
Minat & Pencarian informasi \\
Keinginan & Evaluasi alternatif \\
Tindakan & Keputusan pembelian \\
\hline Sumber: Dokumentasi Penelitian & \\
\hline
\end{tabular}

Sumber: Dokumentasi Penelitian

AIDA adalah singkatan sederhana yang telah dibuat lama sebagai pengingat dari empat tahapan proses penjualan. AIDA singkatan dari Attention, Interest, Desire, Action ini merupakan model yang cukup sederhana dan dapat digunakan sebagai pedoman ((Rofiq, Arifin, dan Wilopo, 2012).

a. Attention (perhatian)

Tahap awal attention ini seorang pemasar haruslah mampu membuat sebuah media informasi agar mengandung daya tarik bagi konsumen. Membuat suatu pernyataan yang mengungkap perhatian orang, membuat kata atau gambar yang powerful yang bisa menarik perhatian hingga orang berhenti dan memperhatikan isi pesan berikutnya.

b. Interest (perhatian)

Interest adalah langkah setelah seorang pemasar mampu untuk membuat sebuah media informasi tersebut agar dapat mengandung daya tarik bagi konsumen, seorang pemasar haruslah memikirkan sebuah media informasi agar dapat mengandung minat bagi calon pelanggan atau konsumennya tersebut.

c. Desire (keinginan)

Selanjutnya langkah yang harus dilakukan oleh seorang pemasar ialah memunculkan keinginan untuk mencoba atau memiliki, dimana dalam tahapan ini pemasar haruslah jeli atau pintar membaca target atau konsumen dalam tahapan ini.

d. Action (tindakan)

Tahapan yang paling pusat ini seorang pemasar haruslah sudah mengarah pada tindakan untuk membeli. Dalam tahapan action ini menjelaskan langkah apa yang dilakukan oleh seorang pemasar dalam menginginkan untuk pembaca atau target melakukan keputusan untuk membeli.

Menurut Kotler (dalam Tehuayo, 2018) terdapat lima proses keputusan pembelian yang dilalui oleh setiap individu dalam melakukan pembelian, yaitu:

a. Problem Recognition (Pengenalan Masalah)

Pengenalan kebutuhan tahap awal keputusan membeli, konsumen mengenali adanya masalah kebutuhan akan produk yang akan dibeli.

b. Information Research (Pencarian informasi)

Tahap pencarian informasi dalam keputusan pembelian dapat merangsang konsumen untuk mencari informasi lebih banyak. Konsumen. 
Cindy Claudia Christine, Roswita Oktavianti: Pengaruh Pesan Persuasif Beauty Vlogger terhadap Keputusan Pembelian

c. Evaluation of Alternatives (Evaluasi alternatif)

Pada tahap ini proses yang dilakukan konsumen untuk mencari dan menggunakan sebanyak-banyaknya informasi atas alternatif pilihan akan barang yang dibutuhkan dan diinginkan yang didapat untuk mengevaluasi.

d. Purchase Decision (Keputusan Pembelian)

Pada tahap ini konsumen telah merencanakan dan mencapai pilihan untuk membeli sebuah produk dan kemudian membeli produk tertentu untuk pemenuhan kebutuhan.

Pendekatan penelitian yang dilakukan dalam penelitian ini adalah kuantitatif, yaitu pendekatan ilmiah terhadap pengambilan keputusan. Menurut Sugiyono, penelitian kuantitatif merupakan penelitian berupa angka-angka dan analisis menggunakan statistik (dalam Agusta dan Susanto, 2013). Menurut Sugiyono, populasi adalah wilayah generalisasi yang terdiri atas objek dan subjek yang mempunyai kualitas dan karakteristik tertentu yang ditetapkan oleh peneliti untuk dipelajari dan kemudian ditarik kesimpulannya (dalam Sinuhaji, 2014).

Dalam penelitian ini, populasi yang diteliti oleh penulis adalah masyarakat yang pernah menonton dan membeli produk yang diulas di akun Youtube Tasya Farasya. Sampel adalah bagian dari sejumlah karakteristik yang dimiliki oleh populasi yang digunakan untuk penelitian. Penelitian ini akan mengambil unit sampel yang terbatas hanya pada orang-orang yang menonton dan membeli produk yang diulas oleh akun Youtube Tasya Farasya.

Teknik sampling yang digunakan peneliti adalah nonprobability sampling yakni teknik pengambilan sampel yang tidak memberikan peluang atau kesempatan yang sama untuk setiap anggota populasi untuk dipilih sebagai sampel penelitian (Sujarweni, 2019:71). Peneliti menggunakan teknik nonprobability sampling dengan pendekatan purposive sampling. Purposive sampling adalah teknik yang digunakan dengan menentukan kriteria khusus terhadap sampel (Prasetyo dan Jannah, 2013:135). Alasan peneliti menggunakan purposive sampling adalah karena tidak semua sampel memiliki kriteria yang sesuai dengan yang peneliti tentukan.

Menurut Roscoe, ukuran sampel yang layak dalam penelitian adalah antara 30 sampai dengan 500. Untuk menentukan jumlah sampel dalam penelitian, banyaknya responden yang digunakan untuk penelitian bergantung pada banyaknya jumlah indikator penelitian dikali 5 (Hair et al, 1995). Dalam penelitian ini terdapat indikator, maka 17 (indikator) x $5=85$ (dibulatkan menjadi 100) responden yang akan menjadi jumlah sampel minimal dalam penelitian ini.

\section{Hasil Penelitian dan Diskusi}

Setelah melalui proses pengolahan data dengan menggunakan Program SPSS diperoleh hasil uji validitas dengan hasil seperti yang ditunjukan tabel 1. Untuk lebih jelasnya, berikut ini akan disajikan hasil uji validitas:

Table 1. Hasil Uji Validitas Variabel X dan Variabel Y

\begin{tabular}{|c|c|c|c|c|}
\hline & No & Butir Indikator & $\begin{array}{c}\text { Corrected } \\
\text { Item Total } \\
\text { Correlation }\end{array}$ & Keterangan \\
\hline \multirow{2}{*}{$\begin{array}{c}\text { Pesan } \\
\text { Persuasif } \\
(X)\end{array}$} & 1 & PP 1 & 0,471 & Valid \\
\cline { 2 - 5 } & 2 & PP 2 & 0,703 & Valid \\
\cline { 2 - 5 } & 3 & PP 3 & 0,606 & Valid \\
\cline { 2 - 5 } & 4 & PP 4 & 0,709 & Valid \\
\hline
\end{tabular}




\begin{tabular}{|c|c|c|c|c|}
\hline & 5 & PP 5 & 0,583 & Valid \\
\hline & 6 & PP 6 & 0,667 & Valid \\
\hline & 7 & PP 7 & 0,350 & Valid \\
\hline & 8 & PP 8 & 0,298 & Valid \\
\hline & 9 & PP 9 & 0,316 & Valid \\
\hline \multirow{8}{*}{$\begin{array}{c}\text { Keputusan } \\
\text { Pembelian } \\
\text { (Y) }\end{array}$} & 1 & KP 1 & 0,392 & Valid \\
\hline & 2 & KP 2 & 0,372 & Valid \\
\hline & 3 & KP 3 & 0,426 & Valid \\
\hline & 4 & KP 4 & 0,496 & Valid \\
\hline & 5 & KP 5 & 0,571 & Valid \\
\hline & 6 & KP 6 & 0,373 & Valid \\
\hline & 7 & KP 7 & 0,355 & Valid \\
\hline & 8 & KP 8 & 0,216 & Valid \\
\hline
\end{tabular}

Sumber: Hasil Kuesioner yang diolah dengan SPSS

Dari uji validitas tersebut diketahui bahwa pernyataan dari seluruh variabel adalah valid karena angka korelasi di atas 0.200.

Tabel 2. Uji Reliabilitas

\begin{tabular}{|c|c|c|}
\hline Variabel & Nilai Cronbach's Alpha & Keterangan \\
\hline Pesan Persuasif (X) & 0,823 & Reliabel \\
\hline Keputusan Pembelian (Y) & 0,709 & Reliabel \\
\hline
\end{tabular}

Sumber: Hasil Pengolahan Data SPSS

Berdasarkan hasil uji tabel 2, diketahui bahwa 9 butir pernyataan variabel $\mathrm{X}$ (Pesan Persuasif) memiliki nilai Cronbach's Alpha sebesar 0,823 yang artinya variabel pesan persuasif memiliki instrumen reliabel karena nilai Cronbach's Alpha >0,6.

Tabel 3. Uji Normalitas

\begin{tabular}{|c|c|c|}
\hline & Pesan Persuasif (X) & $\begin{array}{c}\text { Keputusan } \\
\text { Pembelian (Y) }\end{array}$ \\
\hline Hasil Uji Normal & 0,113 & 0,080 \\
\hline
\end{tabular}

Sumber: Hasil Pengolahan Data SPSS

Dalam penelitian ini, peneliti menggunakan uji One Sample Kolmogorov Smirnov yang ada pada aplikasi SPSS. Uji normalitas ini digunakan untuk mengetahui sebuah data normal atau tidak. Hasil analisis di atas menunjukkan bahwa ada nilai signifikansi sebesar 0,113 untuk variabel $\mathrm{X}$ dan 0,080 untuk variabel $\mathrm{Y}$. Hasil tersebut menyatakan bahwa distribusi data berdistribusi secara normal karena nilai signifikansi $\mathrm{X}$ dan $\mathrm{Y}>0,05$.

Tabel 4. Hasil Uji Koefisien Korelasi

\begin{tabular}{|l|r|r|r|r|}
\hline Model & $\mathrm{R}$ & $\mathrm{R}$ Square & $\begin{array}{c}\text { Adjusted R } \\
\text { Square }\end{array}$ & $\begin{array}{c}\text { Std. Error of the } \\
\text { Estimate }\end{array}$ \\
\hline 1 & $.628(\mathrm{a})$ & .394 & .388 & 2.636 \\
\hline
\end{tabular}

Sumber: Hasil Pengolahan Data SPSS 
Cindy Claudia Christine, Roswita Oktavianti: Pengaruh Pesan Persuasif Beauty Vlogger terhadap Keputusan Pembelian

Dari hasil perhitungan Tabel 4, diketahui bahwa nilai koefisien korelasi $\mathrm{R}$ sebesar 0,628 yang berada di antara interval $0,60-0,799$ artinya pesan persuasif mempunyai hubungan yang kuat terhadap keputusan pembelian.

Tabel 5. Hasil Uji Koefisien Determinasi

\begin{tabular}{|l|r|r|r|r|}
\hline Model & $\mathrm{R}$ & R Square & $\begin{array}{c}\text { Adjusted R } \\
\text { Square }\end{array}$ & $\begin{array}{c}\text { Std. Error of the } \\
\text { Estimate }\end{array}$ \\
\hline 1 & $.628(\mathrm{a})$ & .394 & .388 & 2.636 \\
\hline
\end{tabular}

Sumber: Hasil Pengolahan Data SPSS

Dari hasil perhitungan Tabel 5 diketahui bahwa nilai koefisien determinasi pada tabel R Square sebesar 0,628 menunjukkan bahwa 39,4\% keputusan pembelian dipengaruhi oleh pesan persuasif sementara sisanya $60,6 \%(100 \%-39,4 \%)$ dipengaruhi oleh faktor lain.

Tabel 6. Hasil Regresi Linear Sederhana

\begin{tabular}{|ll|r|r|r|r|r|}
\hline \multirow{2}{*}{ Model } & & \multicolumn{2}{|c|}{$\begin{array}{c}\text { Unstandardized } \\
\text { Coefficients }\end{array}$} & $\begin{array}{c}\text { Standardized } \\
\text { Coefficients }\end{array}$ & $\mathrm{t}$ & Sig. \\
\cline { 3 - 7 } & & \multicolumn{1}{c|}{$\mathrm{B}$} & Std. Error & Beta & \multicolumn{1}{c|}{ B } & Std. Error \\
\hline 1 & (Constant) & 17.902 & 1.988 & & 9.007 & .000 \\
& T.X & .428 & .054 & .628 & 7.979 & .000 \\
\hline
\end{tabular}

Sumber: Hasil Pengolahan Data SPSS

Berdasarkan Tabel 6, maka persamaan di atas dapat diartikan, nilai sebesar 17.902 menyatakan konstanta dari fungsi regresi yang menunjukan bahwa jika tidak ada kenaikan variabel X (Pesan Persuasif), maka variabel Y (Keputusan Pembelian) akan mencapai 17.902. Setiap ada penambahan 1 angka atau perubahan variabel $X$ (Pesan Persuasif), maka variabel Y (Keputusan Pembelian) akan mengalami peningkatan sebesar 0,428. Hal ini dapat dikatakan hasil uji $\mathrm{T}$ pada variabel $\mathrm{X}$ adalah Ho ditolak dan Ha diterima, artinya terdapat pengaruh Pesan Persuasif terhadap keputusan Pembelian.

Tabel 7. Hasil Uji T

\begin{tabular}{|ll|r|r|r|r|r|}
\hline \multirow{2}{*}{ Model } & & \multicolumn{2}{|c|}{$\begin{array}{c}\text { Unstandardized } \\
\text { Coefficients }\end{array}$} & $\begin{array}{c}\text { Standardized } \\
\text { Coefficients }\end{array}$ & $\mathrm{t}$ & \multicolumn{1}{c|}{ Sig. } \\
\cline { 3 - 7 } & & \multicolumn{1}{c|}{ B } & Std. Error & Beta & \multicolumn{1}{c|}{ B } & Std. Error \\
\hline 1 & (Constant) & 17.902 & 1.988 & & 9.007 & .000 \\
& T.X & .428 & .054 & .628 & 7.979 & .000 \\
\hline
\end{tabular}

Sumber: Hasil Pengolahan Data SPSS

Tabel 7 menunjukkan dari hasil analisis data diketahui bahwa nilai $\mathrm{t}=7.979$ dan tingkat signifikansi $=0,000<0,05$. Karena nilai $\mathrm{p}<0,05$, maka $\mathrm{H}_{0}$ ditolak dan Ha diterima, yang berarti terdapat pengaruh positif Pesan Persuasif terhadap Keputusan Pembelian. 


\section{Kesimpulan}

Berdasarkan hasil uji koefisien korelasi, diketahui bahwa nilai korelasi berada di antara interval 0,60-0,799 yang menunjukkan pesan persuasif memiliki hubungan yang kuat terhadap keputusan pembelian. Dengan demikian, semakin meningkatnya pesan persuasif maka keputusan pembelian juga akan meningkat. Sebaliknya bila pesan persuasif menurun maka keputusan pembelian juga akan menurun.

Berdasarkan hasil uji hipotesis pesan persuasif (X) terhadap keputusan pembelian (Y), Ho ditolak dan Ha diterima, artinya bahwa terdapat pengaruh pesan persuasif terhadap keputusan pembelian sebesar 39,4\% keputusan pembelian dipengaruhi oleh pesan persuasif, sementara sisanya $60,6 \%$ dipengaruhi oleh faktor lain.

\section{Ucapan Terima Kasih}

Ucapan terima kasih ditujukan kepada Universitas Tarumanagara Fakultas Ilmu Komunikasi dan kepada responden penelitian yang telah banyak membantu selama proses penelitian ini berlangsung sampai dengan pembuatan artikel jurnal ini.

\section{Daftar Pustaka}

Agusta, L., \& Susanto, E. M. (2013). Pengaruh Pelatihan dan Motivasi Kerja Terhadap Kinerja Karyawan CV Haragon Surabaya. Jurnal AGORA.

Agustiara, R., Okatini, M., \& Jumhur, A. A. (2019). Effect of Beauty Vlogger Testimonial (Review) On Consumer Interest (Viewers) On Cosmetic Products. Jurnal Jobs, Vol.5, No.2. 149-156.

Bungin, Burhan. (2011). Penelitian Kualitatif. Jakarta: Kencana Predana Media Group.

Devito, Joseph A. (2011). Komunikasi Antar Manusia. Pamulang-Tangerang Selatan: Karisma Publishing Group.

Effendy, Onong Uchjana. (2016). Komunikasi teori dan praktek. Bandung: PT. Remaja Rosdakarya.

Kriyantono, Rahmat. (2006). Teknik Praktis Riset Komunikasi. Jakarta: PT. Kencana Perdana. 